American Journal of Environmental Sciences 4 (4): 406-411, 2008

ISSN 1553-345X

(C) 2008 Science Publications

\title{
Phytoplankton Diversity as Indicator of Water Quality for Fish Cultivation
}

\author{
${ }^{1}$ Arunava Pradhan, ${ }^{1}$ Pranami Bhaumik, ${ }^{1}$ Sumana Das, ${ }^{1}$ Madhusmita Mishra, \\ ${ }^{3}$ Sufia Khanam, ${ }^{3}$ Bilqis Amin Hoque, ${ }^{2}$ Indranil Mukherjee, \\ ${ }^{1}$ Ashoke Ranjan Thakur and ${ }^{1}$ Shaon Ray Chaudhuri \\ ${ }^{1}$ Department of Biotechnology, West Bengal University of Technology, BF-142, \\ Sector 1, Salt Lake, Kolkata 700064, India \\ ${ }^{2}$ Army Institute of Management, Judges Court Road, Alipore, Kolkata 700027, India \\ ${ }^{3}$ Environment and Pollution Research Centre, House\#242, Road\#17, New DOHS, \\ Mohakhali, Dhaka-1206, Bangladesh
}

\begin{abstract}
Waste water fed fisheries are a common feature in different parts of the world. Yet not all work as efficiently as those operating at East Calcutta Wetland for more than 70 years now. The objective of this study is to unravel the reason for the markedly greater efficiency of the Bheris in fish production compared to other water bodies like rain water ponds or sewage fed fish ponds elsewhere. The study indicates that plankton growth could be an important factor responsible for greater fish production in the Bheris. The architecture of the Bheri itself acts as a facilitator in the process. It is proposed that planktons can act as biomarker for water quality assessment in fish production.
\end{abstract}

Key words: Plankton, bheri, khamar, dighi, east calcutta wetland

\section{INTRODUCTION}

The potential of waste water fed aquaculture has long been recognized in Asia, and the history of such systems goes back over several centuries ${ }^{[1]}$. The traditional systems in China involve the collection of human excreta for use as fertilizer for fish culture. Since 1950s the use of municipal waste water has developed rapidly. In Germany scientists have studied waste water fed aquaculture since the late $19^{\text {th }}$ Century $^{[2]}$ while in India it began around 1930. The Calcutta waste water fish pond system has the advantage of not only the production of fish but also improvement in water quality and reduction of pathogens in the sewage ${ }^{[3]}$.

East Calcutta Wetland (ECW) is a perfect example of wise-use wetland ecosystem where usage of city sewage for traditional practices of fisheries and agriculture is practiced. The wetland ecosystem is a rare example of combination of environmental protection and development management. ECW also happens to be the largest ensemble of sewage fed fish ponds in the world in one place ${ }^{[4,5,6,7]}$. The tropical regions are more suitable for treating sewage in ponds. Bheri, the flat bottom shallow waste water fed fish ponds, a specialty of the eastern part (mostly West Bengal) of India has been reported to be the best example of integrated resource recovery. Here the waste water is naturally processed and utilized for the cultivation of fishes. After fish cultivation the water is used for irrigation of the surrounding fields and the effluent at the bottom of the Bheri is used as a fertile soil for the same fields. These waste water fed fish ponds are different from the other waste water fed ponds operating in different countries in certain features. The first among these is their shallow depths $(50$ to $150 \mathrm{~cm})$ and flat bottoms ${ }^{[8]}$. This ensures that sunlight penetrates evenly to the bottom of the ponds and results in photosynthetic activity within these ponds which is the basis of natural biological purification. There is a drastic reduction in coliform count between the water of the raw sewage canal and the corresponding Bheri.

One of the possible explanations for the purification process operating at Bheri is the alkalinity developed due to processing of the pond bed with lime. This elevated $\mathrm{pH}$ is fatal for the coliforms and leads to their reduction. The solar energy that is trapped by a dense population of plankton which in turn are consumed by the fishes may be another cause. The planktons play a significant role in degrading the organic matter. But overgrowth of planktons becomes a problem for pond management since they cause algal bloom. It is at this critical phase of the ecological process that the fish plays an important role by grazing

Corresponding Author: Shaon Ray Chaudhuri, Department of Biotechnology, West Bengal University of Technology, BF-142, Sector 1, Salt Lake, Kolkata 700064, India 
on the plankton. The two fold role played by the fishes is indeed crucial - they maintain a proper balance of the plankton population in the pond and also convert the available nutrients in the wastewater into readily consumable form (fish) for humans. Among the diverse variety of planktons, there are some like the cyanobacteria which produce toxins that are detrimental for fish growth and quality but there are the green algae which are known to facilitate fish growth $^{[9,10]}$. Thus the planktons can themselves be classified as useful and harmful from the angle of waste water fed fish production. The fish farmers of ECW have developed such a mastery of these resource recovery activities that they are easily growing fish at a yield which is 2 to 4 times higher than normal ponds at production costs unmatched by any other freshwater fish ponds of this country ${ }^{[11]}$. On the other hand the sewage fed fish ponds in the tropical neighboring country of Bangladesh are not showing as much production and even the production that is obtained is not consistent.

The pond system at ECW functions in a systematic manner involving five major phases. The first is pond preparation which involves complete draining of the ponds, sun drying of the pond bottom, desilting of silt traps, tilling and repairing of dikes. During this stage there is treatment of the soil with lime which ensures alkalinity of the introduced water. This alkalinity also leads to decreased coliform count. This is mostly in December and January. The second phase is called primary fertilization where waste water is introduced into the Bheri and allowed to undergo natural purification. The pond is stirred intensely to reduce anaerobic conditions in the sediments and promote the development of benthic organisms which would be used as fish feed. This is in the middle of February. The third phase involves fish stocking. This starts in the middle of March. To ascertain the quality of water for fish growth, initially stocking test fish is done in which a small number of fish is stocked as probe species to test water quality. After obtaining satisfactory water quality, proper fish stocking takes place. The fourth phase is that of secondary fertilization in which there is periodic introduction of waste water into the ponds throughout the growth cycle. Sewage is added to the fishpond to stimulate sufficient plankton growth for fish feed. Care is taken to maintain the dissolved oxygen concentration above the threshold level for fish sustenance. The final phase involves the fish harvesting which starts from August and continues to December till the phase one starts. Thus the cycle continues ${ }^{[8]}$. On the other hand, the waste water fed fish pond (locally called Khamar) preparation at Bangladesh also starts in
November and December where once every year the ponds (300 to $610 \mathrm{~cm}$ deep) are dried, the top layer of soil is removed and the bed treated with lime and potash which is impure form of potassium carbonate mixed with other potassium salts. The water is treated again with common salt and potash in case of any fish disease out break. As feed they add additionally urea, musted cake, rice dust, wheat brain, boiled rice pellet once every week. The fish growth is best between July to September which is followed by harvesting.

This study attempts to analyze the variation in physicochemical as well as plankton profile of the waste water fed ponds bodies from the two countries in order to understand the cause for the variation of fish production. It would also involve comparison of the fresh water ponds with waste water fed fish pond from India to understand the relation between the water source and the other parameters, if any. This study intends to look for biomarkers, if any, as quality indicator for fish production in such ponds.

\section{MATERIALS AND METHODS}

Collection of water sample: The water samples were collected in sterile plastic containers from a depth of 1.5 to $2.0 \mathrm{~cm}$ below the surface of the water and transported to the laboratory for further analysis at $4^{\circ} \mathrm{C}$. Samples were collected from four different Bheris at ECW (from India) namely Captain Bheri, Natar Bheri, Nuner Bheri (No.-1) and Charakdanga Bheri; four different Khamars (from Bangladesh) namely: Bawniabad Dhigi 1, Bawniabad Dhigi 2, Bawniabad Dighi 3 and Gulshan Lake as well as four rain water ponds from New Barrackpur, India, a site distant from ECW and thus no way related to Bheri. In addition two other rainwater ponds from India, one from Salt Lake (Central Park Pond) which is close to ECW and another from Ichapore which is further away from New Barrachpur were taken in order to avoid any artifact in the study by ensuring wide spread distribution. Being spread over a large region, thirty aliquots of water samples were collected from different parts of each Bheri and the rain water ponds.

Physicochemical analysis: Chloride (kit: Model CD-B chloride test Cat. No. 26018-00, HACH), Nitrate (Model NI-11 Cat. No.1468-03, HACH) and Ammonia Nitrogen (Model NI- 8 Cat. No.2241-00, HACH) were monitored using kits from $\mathrm{HACH}$ as per the manufacturers protocol. The sensitivity of these were 0 $400 \mathrm{mg} / 1$ (miligram per liter), $0-50 \mathrm{mg} / \mathrm{l}$ and $0-3 \mathrm{mg} / \mathrm{l}$ respectively. The dissolved oxygen (DO-5509, Lutron), conductivity (Model: 6-7004-02, IS-TD Scan 4, Singapore), turbidity (HI 93703, Microprocessor 
Turbidity meter, HANNA) and $\mathrm{pH}$ (Wegtech Potatest $\mathrm{pH}$ meter) were measured as per the standard protocol. The detection limit for these were 0 to $20.0 \mathrm{mg} / 1,20$ to $200 \mathrm{~S}$ (Siemens), 0 to 1000 FTU (Formazin Turbidity Unit) and 0.00 to 14.00 respectively.

Faecal Coliform Count: The samples were used for total faecal coliform measurement according to the protocol provided in Standard Method for the examination of Water and Wastewater Analysis by American Public Health Association, Washington, D.C. (1998). The membrane filtration method of measurement of Total faecal coliform bacteria was performed on the samples. This approach estimates the number of FC colonies present. The DIFCO dehydrated mFC Broth base, BDH Agar powder and rosalic acid were used to make the culture medium in $50 \times 12 \mathrm{~mm}$ disposable plastic petri dishes. The filtered volumes were determined based on pre-testing of several decimal volumes of a few samples from the first 2 batches of every survey. The petri dishes were placed in an incubator for 24 hours at $44.5^{\circ} \mathrm{C}$. The colonies produced by fecal coliform bacteria on $\mathrm{mFC}$ medium in various shades of blue color were counted. Then the counts were calculated according to the dilution factor and reported as Colony forming units per $100 \mathrm{ml}$.

Saturation study: Water in each falcon was mixed by inversion and $20 \mu \mathrm{l}$ was observed under the light microscope. The number of observation and the different varieties of microscopic bodies (plankton) observed were noted and a graph was plotted with number of observation on the $\mathrm{X}$ axis and the total number of newer varieties observed with each observation on the $\mathrm{Y}$ axis. The curve indicates whether saturation in screening the diversity has been obtained as had been shown earlier for a different system ${ }^{[12]}$. It was done for each water body.

Plankton diversity study: Water from different water bodies as mentioned above, were observed under 40X magnification (Phase contrast) of Axiostar Plus fluorescence microscope from Zeiss for identification of different planktons existing there. The different varieties were monitored and identified. The count for different plankton species was taken with haemocytometer.

\section{RESULTS AND DISCUSSION}

Saturation Curves: The number of planktons were counted and thirty independent sets of observations were taken. When the number of observations was plotted on the $\mathrm{X}$ axis and the number of total new varieties observed till a particular observation on the $\mathrm{Y}$ axis for each water body, a saturation curve was

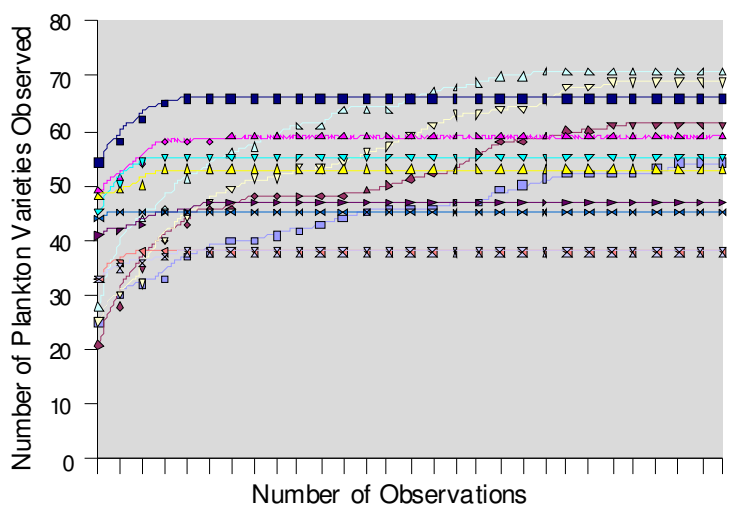

Fig. 1: Figure showing the saturation curve for each water body. Irrespective of the nature of the water body the saturation in plankton diversity is obtained indicating that no further increase in the plankton diversity would be achieved with further increase in the number of observations

Table1: Comparison of coliform count (cfu $100 \mathrm{~mL}^{-1}$ ), conductivity (S) and DO (mg L $\left.{ }^{-1}\right)$ among Bheri and its corresponding raw sewage canal (RSC) in case of Charakdanga Bheri, Nunar Bheri and Captain Bheri from East Calcutta Wetland, Indi

\begin{tabular}{llll}
\hline Site & Conductivity & DO & TTC \\
\hline Charakdanga Bheri & 0.90 & 3.7 & 5005 \\
Charakdanga RSC & 1.00 & 2.6 & Uncountable $\left(>10^{5}\right)$ \\
Nunar Bheri & 0.40 & 4.3 & 180 \\
Nunar RSC & 0.70 & 2.9 & Uncountable $\left(>10^{5}\right)$ \\
Captain Bheri & 1.6 & 3.8 & 1090 \\
Captain RSC & 1.7 & 3.7 & 23200 \\
\hline
\end{tabular}

obtained (Fig 1). This clearly depicts that the screening was adequate and that no further observation for understanding the diversity was needed.

Water quality improvement: Water flows from the Raw sewage canal to the Bheri. A comparison of the profiles of the the two indicates a sharp decrease in coliform count, slight decrease in the conductivity and a slight increase in DO in the Bheri as compared to the corresponding Raw Sewage Canal (Table 1). The results indicate purification of the water in the Bheri.

Further the similar parameters were compared among the different water bodies from the two countries (data not shown). There was no major variation in the different physicochemical parameters that were monitored among the different sites that could emphasize the variation in fish production or could act as marker for indicating the fish producing ability of a water body.

Plankton Diversity: The different water bodies were analyzed for their total plankton count per 
Am. J. Environ. Sci., 4 (4): 406-411, 2008

Table 2: Table indicating the total variety of planktons observed, the total planktons $/ \mathrm{ml}$ and the planktons useful for fish growth per $\mathrm{ml}$ in the different water bodies

\begin{tabular}{llll}
\hline Name of Water Body & Total variety & Total Plankton count/ml & Useful Plankton count/ml \\
\hline Captain Bheri (ECW, India) & 63 & 3601200 & 244000 \\
Nunar Bheri (ECW, India) & 57 & 2018000 & 831000 \\
Natar Bheri (ECW, India) & 55 & 2380000 & 950000 \\
Charakdanga Bheri (ECW, India) & 58 & 2369300 & 905000 \\
Rain water pond 1 (New Barrackpur, India) & 47 & 204600 & 79400 \\
Rain water pond 2 (New Barrackpur, India) & 38 & 129200 & 53000 \\
Rain water pond 3 (New Barrackpur, India) & 50 & 208600 & 83600 \\
Rain water pond 4 (New Barrackpur, India) & 38 & 165800 & 63200 \\
Rain water pond 5 (Ichapore, India) & 61 & 240815 & 93165 \\
Central Park Pond (Salt Lake, India) & 45 & 720800 & 22400 \\
Bawniabad Dighi 1 (Bangladesh) & 66 & 251200 & 89800 \\
Bawniabad Dighi 2 (Bangladesh) & 59 & 162200 & 69200 \\
Bawniabad Dighi 3 (Bangladesh) & 55 & 206200 & 80200 \\
Gulshan Lake (Bangladesh) & 53 & 304400 & 139800 \\
\hline
\end{tabular}

Table 3: Table enlisting the known bioremedial functions of the different planktons found in the various water bodies studied in this paper

\begin{tabular}{ll}
\hline Species & Role in Bioremediation \\
\hline Chlorella & Uptake metals like cadmium, copper, iron, nickel, zinc. \\
Eudorina & Removal of lead, copper, chromium, cadmium. \\
Chlorococcum & Biosorption of metals like lead. \\
Scenedesmus & Absorb and degrade endocrine disrupting insecticide alpha endosulfan. \\
Haematococcus & Bioremediation of crude oil, $\mathrm{n}$ alkanes, polycyclic aromatic hydrocarbons, removal of nitrogen from waste water. \\
Spirullina & Removal of nitrogen and phosphorous from waste water. \\
Nostoc & Removal of copper, mercury cadmium ammonia nitrogen. \\
Closteridium & Metabolism dependent cellular uptake of copper. \\
Navicula & Transformation of $1,1,1-$ Trichloroethane, trichloromethane and tetrachloromethane used in pesticides. \\
Oscillatoria & Accumulation of cadmium, mercury \\
Ulothrix & Accumulation of cadmium, mercury, lead. \\
Anabena & Accumulation of cadmium, mercury, lead. \\
Stichococcus bacillaris & Uptake of radionucleotides such as Co and Cs \\
Synedra & accumulated inorganic lead (Pb) from aqueous solutions extra- and intracellularly. \\
Ankistrodesmus & Intracellular accumulation of mercuric chloride \\
Fragilaria & Accumulate cadmium \\
Selenastrum & Accumulate Cadmium upto 2.25 of its dry weight \\
Euglena & Accumulate Uranium upto $1 \%$ of its dry weight. \\
& Accumulate Aluminium, zinc, manganese, copper and lead \\
\hline
\end{tabular}

milliliter of water, number of total varieties found in each and the total number of useful (from the point of fish growth) varieties of Plankton found per milliliter of water for each (Table 2). The useful varieties were determined from the existing literature ${ }^{[9,10]}$.

The Bheries are known for their fish production for more than 70 years now and are showing the highest plankton count (both total as well as useful). The rain water ponds show moderate fish production. Gulshan Lake shows good fish production most of the time including when the sampling was done. It is reflected in its count of useful plankton $\mathrm{mL}^{-1}$. Bawniabad Dhigi 1 shows better production of fish among the water bodies in Bawniabad with Bawniabad Dhigi 3 as the intermediate producer and Bawniabad Dhigi 2 as the worst among them. In all cases these produce much less fish than the Bheris. This is clearly reflected from the useful plankton count $\mathrm{mL}^{-1}$ in these water bodies.
These useful planktons include Chlorella, Crucigenia, Spirulina, Nitzchia, Scenedesmas, Cyclotella, Microcystis, Coelastrum, Melosira, Navicula, Anabaena, Chlamydomonas, Tetraedon, Euglena, Endorina, Ankistrodesmas, Cosmarium, Fragilaria, Pediastrum and Syndera.

Plankton diversity in Bheri- putative role in bioremediation: A wide variety of planktons are observed from the analysis of water from different Bheris as well as from rain water bodies. The main aim was to find out the relation, if any, between the existence of differential number of the planktons and their bioremedial activity in the water bodies. The bioremedial function for the planktons observed in these bodies as reported by previous studies are listed in Table $3^{[13,14,15,16,17,18,19]}$. As evident from above studies, planktons have a major role in bioremediation. Several studies have put forward the active role of Chlorella 
vulgaris in removal of heavy metal contamination from water and soil. Chlorella tablets are reported to absorb the mercury released during the replacement of mercury amalgam fillings ${ }^{[20]}$. The microalgal strains sequester or precipitate metals/radionucleotide either by surface adsorption, intracellular accumulation or by conditioning the surrounding chemical environment, thus bioconcentrating the meta/radionucleotide in a small volume. Organic contaminants are degraded and may be completely mineralized ${ }^{[21,22]}$.

The plankton diversity analysis in bheris, Dhigi (Khamar) and fresh water indicates one primordial observation, i.e. the different species of planktons were found in high numbers (total plankton count per milliliter) in bheris as compared to the other two bodies. The reason could be attributed to the continuous high load of metals, aromatic compounds and other wastes in the Bheris as compared to the fresh water fed pond or Dhigi. The Gulshan Lake receives industrial effluents from time to time and thus shows an elevated quantity of useful planktons as compared to the other rain water ponds and Dhigi. Abundance of species like Chlorella in Bheris indicates the high concentration of metals like $\mathrm{Ni}, \mathrm{Pb}, \mathrm{Cu}$ in the water body .The source of these metals comes from small scale industries involved in electronic good manufacturing, handicraft etc. High load of metals like chromium are drained into Bheris along with effluents of tanneries as is also reflected by the large number of Chlamydomonas sp. Thus the abundance of different planktons in Bheri as compared to the fresh water ponds is in correlation with their active participation in bioremediation process taking place in this complex ecosystem. The metal concentration of water from different Bheris as analyzed through Energy Dispersive $X$ Ray Fluorescence validates the above statement (results not shown).

\section{CONCLUSION}

The objective of this study was to understand the underlying reason for enhanced fish production in the Bheri as compared to rain water ponds as well as sewage fed fish ponds in other places. From the results of this study it appears that the growth of useful planktons might be an important factor for the fish production. One of the facilitators for this growth is the architecture of the Bheri. The planktons not only enhance fish production but also facilitate bioremediation of heavy metals and other toxic material. In this paper we propose that the above mentioned useful planktons can act as biomarker for water quality assessment for fish production. It is perceived that the process adopted in the Bheris of East Calcutta Wetland might be employed productively in tropical countries like Bangladesh for enhancing their fish production and managing their liquid waste more efficiently. The process of transfer of this technology would be the subject of our future work.

\section{ACKNOWLEDGEMENT}

The authors would like to acknowledge the financial support of Department of Biotechnology, India; West Bengal University of Technology, India; Environment and Population Research Centre, Bangladesh as well as Department of Atomic Energy, India under the Board of Research in Nuclear Sciences scheme. They would like to thank Bioinormatics Infrastructure Facility (DBT, GOI supported) of West Bengal University of Technology for its computational facility. Authors from WBUT would also like to acknowledge the assistance of Prof S K Dey, Mrs Indrani Roy and Ms Poonam Nasipuri of Department of Biotechnology, West Bengal University of Technology, Calcutta during the work. Authors from EPRC would like to acknowledge the help extended by Sanowar Hossain, Bikash C. Roy and people of Bauniabad.

\section{REFERENCES}

1. Chan, G., L.T. Hung and N.V. Thu, 1993 National Seminar on Sustainable livestock production on local resources. pp: 2-10

2. Prein, M. 1990 Wastewater-fed fish culture in Germany. In Wastewater-fed aquaculture (Editors: P Edwards and RSV Pullin),. UNDP-World Bank, Water and sanitation Program, Asian Institute of Technology and ICLARM. P:13-41.

3. http://www.utafoundation.org/utacambod/msc99th es/Sophinlr.htm accessed on 23rd October 2007.

4. http://www.wwfindia.org/about_wwf/what_we_do/ freshwater_wetlands/our_eork/ramsar_sites/east_ca lcutta_wetlands_.cfm /ramsar_sites/east_calcutta_wetlands_.cmf accessed on $14^{\text {th }}$ June 2007.

5. http://www.keip.in/east_kolkata_wetland.htm accessed on $14^{\text {th }}$ June 2007.

6. Ray Chaudhuri, S., S. Salodkar, M. Sudarshan and A.R. Thakur, 2007. Integrated Resource Recovery at East Calcutta Wetland how safe is these? Am. J. Agric. Biol. Sci, 2: 75-80.

7. Ray Chaudhuri, S., M. Mishra, P. Nandy and A.R. Thakur, 2008. Waste management: A case study of ongoing traditional practices at East Calcutta Wetland. Am. J. Environ. Sci. 4(2): 140-144. 
8. http://www.cepis.opsoms.org/muwww/fulltext/repi nd53/calcutta/calcutta.html. Accessed on 20th October 2007.

9. Komarkova, J. 1998. Fish stock as a variable modifying trophic pattern of phytoplankton. Hydrobiologia, 369-370: 139-152.

9. Morabito, G. and A. Oggioni, 1999. Long term evolution (1986-1998) of phytoplankton communities in a shallow manipulated lake (L.Candia, Northern Italy). 2nd European Phycological Congress. Montecatini Terme (Italy) September, 20-26.

10. http://www.ecotippingpoints.org/indepth/indiawetl ands.html (Accessed on 14th June 2007).

12. Raychaudhuri, S. and A.R. Thakur, 2006. Microbial genetic resource mapping of East Calcutta Wetland. Curr. Sci. 91(2): 212-217.

13. Mehta, S.K., 2005. Use of algae for removing heavy metal from waste water : Crit. re. biotechnol. 25(3): 113-152.

14. Ibrahim, M. B.M. and H.A. Gamila, 2004. Algal bioassay for evaluating the role of algae in bioremediation of crude oil; Bull. Envioron. Contam. Technol., 73 (5): 883-889.

15. Voltonica, D., H.G. Villa, and G. Correa, 2005. Nitrogen removal and recycling by Scenedesmus obliqqus in semicontinious cultures using artificial wastewater and a simulated light and temparature cycle. Bioresour. Technol., 96 (3): 359- 362.
16. Chojnacka, K., A. Chojnack, and H. Gorecka, 2003. Trace element removal by Spirulina sp. from copper smelter and refinery effluents, Hydrometallurgy, 73 (1-2): 147-153.

17. Verma, S.K. and S.P. Singh, 1990. Factors regulating copper uptake in a cyanobacterium. Current Microbiol., 21 (100): 33-37

18. Hassett, J.M., J.J. Charles, and J.E. Smith, 1981. Microplate Technique for Determining Accumulation of Metals by Algae. Applied and Environmental Microbiology, 41 (5): 1097-1106.

19. Fujita, M., and K. Hashizume, 1975. Status of uptake of Mercury by the fresh water diatom Synedra ulna. Water research, 9(10): 889-894.

20. Matsunaga, T., H. Takeyama, T. Nakao, and A. Yamazawa,1990. Screening of marine microalgae for bioremediation of cadmium polluted sea water. J Biotechnol., 70(1-3): 33-38.

21. Bender, J. and P. Phillips, 2004. Microbial mats for multiple applications in aquaculture and bioremediation. Bioresource Technology. 94(3): 229-238.

22. Chan, S.M.N., T. Luan, M. H. Wong, and N. F. Y. Tam, 2006. Removal and biodegradation of polycyclic aromatic hydrocarbons by Selenstrum capricornutum. Environ. Toxicol. Chem., 25(7): 1772-1779. 